\title{
Validation of Salinity Data from Surface Drifters
}

\author{
G. Reverdin,* S. Morisset, ${ }^{*}$ J. Boutin, ${ }^{*}$ N. Martin, ${ }^{*}$ M. Sena-Martins, ${ }^{+}$F. Gaillard, ${ }^{\#}$ \\ P. BlOUCH,${ }^{@}$ J. ROLLAND,${ }^{@} J$. FONT,,${ }^{\&}$ J. SALVADOR, ${ }^{\&}$ P. FERNÁNDEZ,${ }^{\&}$ AND D. STAMMER ${ }^{+}$ \\ * LOCEAN/IPSL, UMR CNRS/UPMC/IRD/MNHN, Paris, France \\ ${ }^{+}$Center for Earth System Research and Sustainability, Universität Hamburg, Hamburg, Germany \\ \# Laboratoire de Physique des Océans, Ifremer, Plouzané, France \\ ${ }^{\circledR}$ Centre de Météorologie Marine, Météo-France, Brest, France \\ ${ }^{\&}$ Institut de Ciències del Mar, Consejo Superior de Investigaciones Científicas, Barcelona, Spain
}

(Manuscript received 29 July 2013, in final form 26 November 2013)

\begin{abstract}
Salinity measurements from 119 surface drifters in 2007-12 were assessed; $80 \%$ [Surface Velocity Program with a barometer with a salinity sensor (SVP-BS)] and 75\% [SVP with salinity (SVP-S)] of the salinity data were found to be usable, after editing out some spikes. Sudden salinity jumps are found in drifter salinity records that are not always associated with temperature jumps, in particular in the wet tropics. A method is proposed to decide whether and how to correct those jumps, and the uncertainty in the correction applied. Northeast of South America, in a region influenced by the Amazon plume and fresh coastal water, drifter salinity is very variable, but a comparison with data from the Soil Moisture and Ocean Salinity satellite suggests that this variability is usually reasonable. The drifter salinity accuracy is then explored based on comparisons with data from Argo floats and from thermosalinographs (TSGs) of ships of opportunity. SVP-S/ SVP-BS drifter records do not usually present significant biases within the first 6 months, but afterward biases sometimes need to be corrected (altogether, $16 \%$ of the SVP-BS records). Biases start earlier after 3 months for drifters not protected by antifouling paint. For the few drifters for which large corrections were applied to portions of the record, the accuracy cannot be proven to be better than $0.1 \mathrm{psu}$, and it cannot be proven to be better than 0.5 psu for data in the largest variability area off northeast South America. Elsewhere, after excluding portions of the records with suspicious salinity jumps or when large corrections were applied, the comparisons rule out average biases in individual drifter salinity record larger than $0.02 \mathrm{psu}$ (midlatitudes) and $0.05 \mathrm{psu}$ (tropics).
\end{abstract}

\section{Introduction}

Near-surface salinity is largely determined by the global hydrological cycle as well as by the oceanographic circulation and vertical mixing processes (Schmitt 2008). Sparse near-surface salinity observations have been used to detect signatures associated with known modes of climate variability [Cravatte et al. (2009); Singh and Delacroix (2011) in the tropical Pacific; Gordon and Giulivi (2008) for the tropical North Atlantic; and Reverdin (2010) in the North Atlantic] or more recently with anthropogenetically induced climate change (Terray et al. 2012; Durack and Wijffels 2012). Surface salinity is thus considered a key observable of the oceans; yet, it has not been sufficiently

Corresponding author address: Gilles Reverdin, LOCEAN, 4 Place Jussieu, 75252 Paris CEDEX 05, France.

E-mail: gilles.reverdin@locean-ipsl.upmc.fr observed until recently. Some components of the global observing arrays, and in particular Argo floats, provide a low-resolution global network for observing hydrographic parameters, with salinity observations being available from 4 to $10 \mathrm{~m}$ below the surface to a depth of about $2000 \mathrm{~m}$. Those fairly novel data have been instrumental in investigating the oceanic freshwater budget on a global and regional scale (Roemmich et al. 2009; Von Schuckmann et al. 2009; Von Schuckmann and Le Traon 2011; Johnson and Wijffels 2011; Riser et al. 2008).

Extrapolating these observations to the subsurface (below the skin layer) requires some knowledge of nearsurface haline stratification, which is expected to be large in areas of excess freshwater input or strong diurnal temperature stratification. A preliminary study based in particular on Argo vertical profiles (Henocq et al. 2010) indicated that vertical salinity differences between 1 - and 10-m depth higher than 0.1 psu are observed 
in the three oceans, in particular between $0^{\circ}$ and $15^{\circ} \mathrm{N}$, coinciding with the average position of the intertropical convergence zones characterized by high precipitation rates. Other studies based on drifters (Reverdin et al. 2012) and from mooring data (Cronin and McPhaden 1999) have also identified in the tropics near-surface stratification related to local rainfall.

Satellite-based L-band radiometry can be used to monitor salinity in a layer on the order of $1 \mathrm{~cm}$ (Ulaby et al. 1986). This observation is now provided using the European Space Agency's Soil Moisture and Ocean Salinity (SMOS) satellite (Font et al. 2010) and Aquarius/ Satelite de Aplicaciones Cientificas-D (SAC-D; Lagerloef et al. 2010, S70-S71) satellite missions. After applying geophysical corrections on SMOS brightness temperatures and removing data contaminated by radio frequency interference (RFI) or land effects, SMOS sea surface salinity (SSS) reproduces expected variations at large scales (Font et al. 2013; Boutin et al. 2012b; Reul et al. 2012; Banks et al. 2012) as well as rainfall-related signals (Boutin et al. 2012a), but its absolute accuracy as well as the accuracy of Aquarius retrievals are still subject to large uncertainties on the order of 0.3 psu that require sets of validation data. The L-band penetration depth layer is much thicker than the salinity skin-depth layer, usually less than $1 \mathrm{~mm}$ (Zhang and Zhang 2012). Thus, validating/interpreting the satellite data is probably more an issue of subsurface stratification between a few meters and 1-cm depth than a skin-layer effect. The data of drifters and surface buoys instrumented with salinity sensors fairly close to the surface could contribute to this goal, as well as data of instrumented profilers reaching the sea surface or near-surface data on moorings.

To better document the variability of salinity near the sea surface, which is currently not often measured by other in situ observations, Surface Velocity Program (SVP) drifters have been equipped in the last 10 years with Sea-Bird SBE37 with serial interface (SI) conductivity and temperature $(\mathrm{C}-\mathrm{T})$ sensors near a depth of $50 \mathrm{~cm}$. The data of these drifters proved reliable and correctable for midlatitude deployments in the eastern Atlantic Ocean (Reverdin et al. 2007). Since then, two manufacturers of SVP drifters, Metocean and Pacific Gyre (PG), have instrumented SVP drifters with SeaBird SBE37 sensors (Boutin et al. 2011), and have implemented further antifouling protection. In addition, light wave riders called "Surplas" have been built at the Laboratoire d'Océanographie et du Climat (LOCEAN) laboratory to measure conductivity at $17-\mathrm{cm}$ depth for a duration of a few weeks to a few months. Surplas wave riders have been tethered to SVP drifters to study SSS and SST stratification above 50-cm depth (Reverdin et al. 2012, 2013). Since 2007, the Institut de Ciències del
Mar (ICM) of the Consejo Superior de Investigaciones Científicas (CSIC) laboratory has also built SVP-like drifters with SBE37 C-T cells placed near 50-cm depth but without additional antifouling protection. The sampling characteristics of the different drifters are slightly different. The Surplas float provides a value (average over $8 \mathrm{~s}$ ) every $15 \mathrm{~min}$ of $T$ and $S$; the PG SVP with salinity (SVP-S; that is, an SVP model with the SBE37 C-T sensors added) and the SVP with a barometer with a salinity sensor (SVP-BS) drifter, a value every $30 \mathrm{~min}$ (average over $5 \mathrm{~min}$ ); the Metocean SVPBS drifter, a value every hour (average of seven values over $10 \mathrm{~min}$ ); and the ICM/CSIC makes a spot measurement every $10 \mathrm{~min}$, with the latest data telemetered during satellite fixes of the Argos system. A majority of the drifters and surface floats transmitted using the Argos system, although Metocean drifters since 2009 mostly transmit data (and a 3-hourly GPS position) through Iridium communication, and some PG drifters are also recently transmitting with Iridium communication.

Earlier work with salinity drifter data has focused on identifying drifts, in particular those due to fouling in a midlatitude environment, as well as the effect of the position difference between temperature and conductivity sensors on the estimation of salinity (Reverdin et al.2007) or vertical stratification caused by the diurnal cycle (Reverdin et al. 2013). The data have also been used for investigating the effect of precipitation on surface salinity (Reverdin et al. 2012).

In this paper, we discuss the drifter salinity datasets. First, we will comment on the data return of the drifters, and then present our efforts to quality control and correct the data. We will separate data into class A data, for which we can safely estimate the accuracy, and class B data, which are more uncertain. Finally, we will investigate the overall accuracy of the dataset from independent data.

\section{The surface salinity drifter datasets}

Between 2007 and early 2012, 37 Metocean SVP-BS drifters, 40 PG SVP-BS drifters, 17 ICM/CSIC drifters, 17 Surplas floats, and 25 PG SVP-S drifters were deployed (we do not include in these statistics the 5 PG SVP-BS drifters that failed due to mishandling during deployment). More than half of the drifters were deployed in the equatorial and tropical regions, while the others were deployed in the northeast North Atlantic, the Nordic seas, and the Mediterranean Sea. Statistics for the drifter analyzed in this study are summarized in Table 1 (this excludes drifters still alive in January 2013). The positions/trajectories of drifters with validated salinity data are presented in Fig. 1. 
TABLE 1. Overall statistics of the validated drifters in deployments in 2007-12 (for 2012, we did not include drifter still collecting data in January 2013). Class A salinity data are expected to be either 0.02 psu accuracy (mid- and high latitudes) or 0.05 psu accuracy (tropics). Class B data are less accurate data, but they can still be used.

\begin{tabular}{lccccc}
\hline \hline Drifter type & $\begin{array}{c}\text { No. of } \\
\text { drifters } \\
\text { deployed }\end{array}$ & $\begin{array}{c}\text { Average } \\
\text { lifetime } \\
\text { (days) }\end{array}$ & $\begin{array}{c}\text { Average time (days) with drogues } \\
\text { attached (for drifters having had a } \\
\text { lifetime exceeding 250 days) }\end{array}$ & $\begin{array}{c}\text { Average No. of days } \\
\text { with class A data }\end{array}$ & $\begin{array}{c}\text { Average No. of } \\
\text { days with class B data }\end{array}$ \\
\hline PG SVP-BS & 40 & 176 & 276 & 132 & 15 \\
Metocean SVP-BS & 37 & 228 & 237 & 175 & 13 \\
ICM & 17 & 249 & 346 & 449 & 15 \\
PG SVP-S & 25 & 545 & & 82 & \\
\hline
\end{tabular}

The SVP-BS drifters had a lifetime in the water commonly shorter than one year, mostly because of recovery by fishermen (seven drifters recovered in the Bay of Biscay and near the Atlantic region, six near South America/the Caribbean, and one each off the Ivory Coast; West Africa; and off Queensland, Australia), or because of beaching most commonly after a drogue loss. In some instances (in the Bay of Biscay, off the Queensland coast or off the coast of Ireland), the recovery was done on purpose and the drifter redeployed sometime after (then, we consider this as two separate drifters in our count). For a small number of SVP-BS drifters (six Metocean drifters with average an lifetime of 14 months, and one PG drifter with a lifetime of 21 months), the end occurred through normal battery drawdown. On the other hand, this was the case for most SVP-S drifters (except eight). Thus, the average lifetime of SVP-S drifters was longer (586 days including 368 days with the drogue on for the 10 South Pacific drifters) with no early loss due to fishermen or beaching. The average lifetime was 249 days for ICM/CSIC drifters, but we do not have the estimation of drogue loss yet.
Data interruption occurred quickly because of switch problems for four PG SVP-BS drifters, electronic problems for two PG SVP-BS drifters, and unknown reasons for four PG SVP-BS drifters. It also occurred within 2 days after deployment for four SVP-S drifters (in the North Atlantic). For two Metocean drifters, there was a loss of $\mathrm{C}-\mathrm{T}$ data after a little more than 6 months, suggesting an interruption of connection between the Sea-Bird sensors and the electronics inside the buoy hull. There were also three ICM/CSIC drifters when the reported $T$ and $S$ remained at the same value, and other Metocean and PG SVP-BS drifters, as well as most SVP-S drifters, when the $T$ and $C$ values stopped being reported near the end of the life, probably because of low power. For nine Metocean SVP-BS drifters, the end of life probably happened through electronics/circuit problems or a water leak after a short while five presented a visible fast fall of the battery voltage before the drifter's demise.

Drogue loss on SVP-BS drifters happened commonly within less than 8 months at sea. This estimate is based mostly on the drifter submergence sensor, information

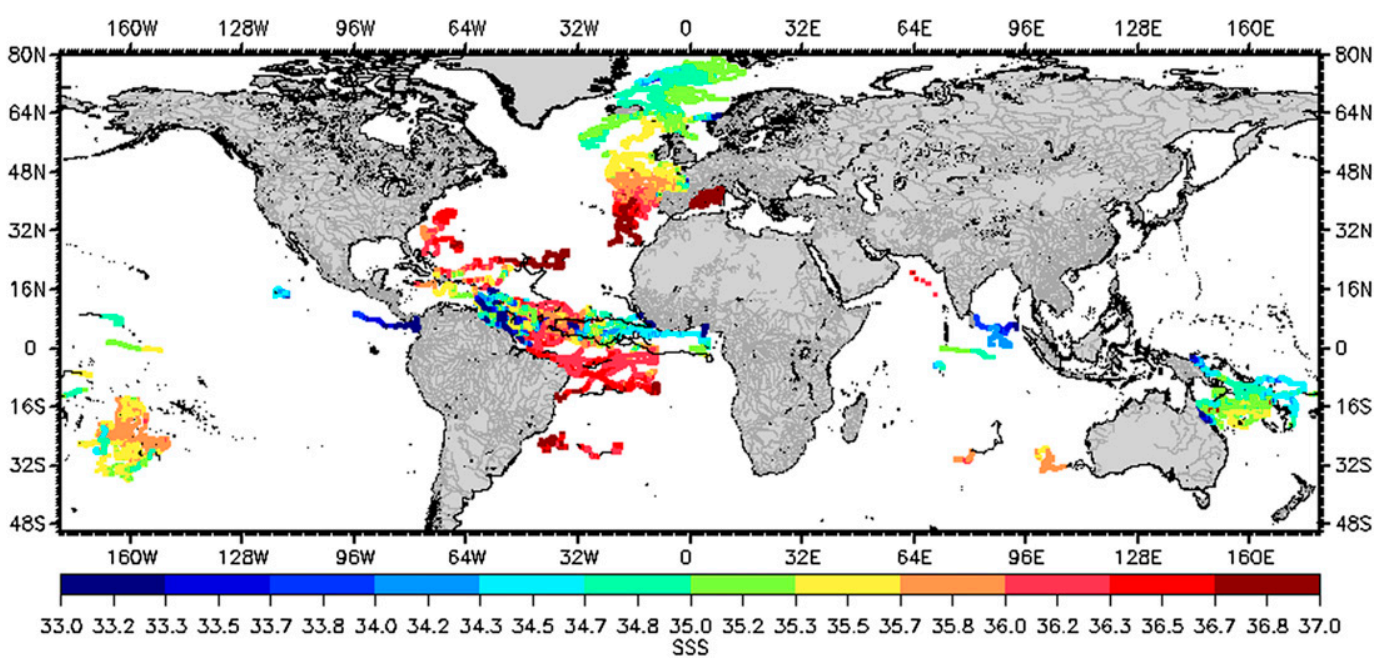

FIG. 1. Trajectories of all drifters with validated salinity data (color coded by salinity; black portions of the trajectories correspond to rejected data). 
that was usually easy to interpret on these drifters (except for some Metocean drifters). When recovery occurred, the observed presence or absence of the drogue was consistent with the indication from the sensor. We did not investigate if this estimate of drogue loss suffers from the errors pointed out by Grodsky et al. (2011) for a smaller subset of drifters commonly deployed in recent years. Drogue loss has some bearing on how to interpret the C-T Sea-Bird data. When drogue is present and there is some wind/waves, we expect that the actual average depth of the $\mathrm{C}-\mathrm{T}$ sensors is a little deeper than the nominal depth, as the buoy hull plunges into waves. When the drogue is absent, the buoy is more likely to follow the sea surface; thus, the sensors will measure a little shallower and flushing of the cell might be weaker.

In other papers, we commented on biases in the hull temperature sensors of the drifters (Reverdin et al. 2007, 2013). On the other hand, we assume that the error on the temperature measurement of the Sea-Bird C-T cell is very small (it should be smaller than $0.01^{\circ} \mathrm{C}$ according to Sea-Bird one year after deployment); thus, we use this $T$ measurement to validate the hull temperature sensor (referred to here as SST). We found rather large $\left(0.5^{\circ} \mathrm{C}\right.$ or larger) anomalies in the hull sensor measurements in 2010 on both Metocean and PG SVP-BS drifters, caused by incorrect calibrations. The problem has disappeared with later deliveries in 2011, but there were other issues with the SST sensor in the 2011 PG SVP-BS drifters (data became very noisy and unusable after a varying time of 2-6 months, probably as the result of leaks).

Five drifters deployed in the Amazon plume or off French Guiana presented at times huge "anomalous" drops of salinity (to less than $20 \mathrm{psu}$ ) that we attributed to algae or floating objects that got stuck in the cell. One of these drifters was recovered, rinsed, and redeployed with no further indication of sensor fouling. Even within the first month after deployment, there were instances of temporary anomalous lowering of salinity due to objects in the cell on data from two SVP-BS PG drifters paired with a Surplas drifter (cf. later section). For most of the ICM/CSIC drifters deployed in the subtropical gyres, large drops in salinity (larger than $1 \mathrm{psu}$ ) occurred within a few months that could be due either to objects stuck in the cells or to fouling, despite antifouling protection of the Sea-Bird sensor. For drops larger than 1 psu, data could usually not be corrected and were removed.

All these considerations taken together result in an average 5 months of potentially usable C-T data of a PG SVP-BS drifter and 6 months for a SVP-BS Metocean drifter. These are larger when retaining only drifters ending naturally through battery drop, but the sample of such drifters is too small for any reliability in the difference. For ICM/CSIC drifters, the statistics are not well established so far, but the length of usable data seems closer to 3 months. Usable salinity records are longer on PG SVP-S drifters, both in the Nordic seas and in the South Pacific subtropical gyre, possibly because the drifters also lived much longer there. At this stage we do not have significant statistics to investigate the drifter data quality in specific regions. However, it seems that results improve with antifouling applied on the drifter, and not just in the cell, and that the ambient conditions in the low salinity regions close to large river outflows, in particular in the northwestern tropical Atlantic off South America, cause more data issues than the mid- or high latitudes of the North Atlantic/Nordic seas or the subtropical gyres.

\section{Identification of erroneous data}

The messages telemetered through Argos (or Iridium) are used to construct time series of $T$ and $S$. For SVP-S and SVP-BS drifters, we retain either repeated messages or messages obtained just once if the checksum provided is coherent with the reported data. We will now briefly summarize how the SVP-BS drifters as well as the ICM/CSIC drifters are validated and how dubious portions of the records are eliminated.

First, we check the temperature measurements. Some isolated measurements are incorrect in the first hours after deployment (because there is a small influence of earlier conductivity cell temperature on estimated salinity) or due to bad transmission (this represents on the order of $0.1 \%$ of data for long-lived PG92546 in the western Pacific Ocean). Associated salinities are removed.

Then, salinity data too erroneous to be corrected are identified and removed. The first step is to visually identify extended periods with unusual high noise level in $S$ (standard deviation larger than $0.05 \mathrm{psu}$, and the variability in $S$ is not correlated to the variability in $T$ ). These data are removed, for example, the data on 1825 June in the top panel of Fig. 2. This is probably mostly caused by objects in the cell or electronic problems, but there is also the possibility in some cases of noise caused by bubbles.

The second step is to filter out isolated salinity spikes. The filter first identifies isolated values deviating from the median of salinity measured between $6 \mathrm{~h}$ before and $6 \mathrm{~h}$ after by more than $0.1 \mathrm{psu}$ and by more than twice the standard deviation $\left(\sigma_{s}\right)$ for the same period. It then checks whether either the previous or the next data point to the outlier suggests a "continuous" increase or decrease (for that, this data point should deviate from the median by more than $1.25 \times \sigma_{s}$ ). If this is not the case, then we consider that the outlier is erroneous. There could be issues with sporadic rain that would induce 

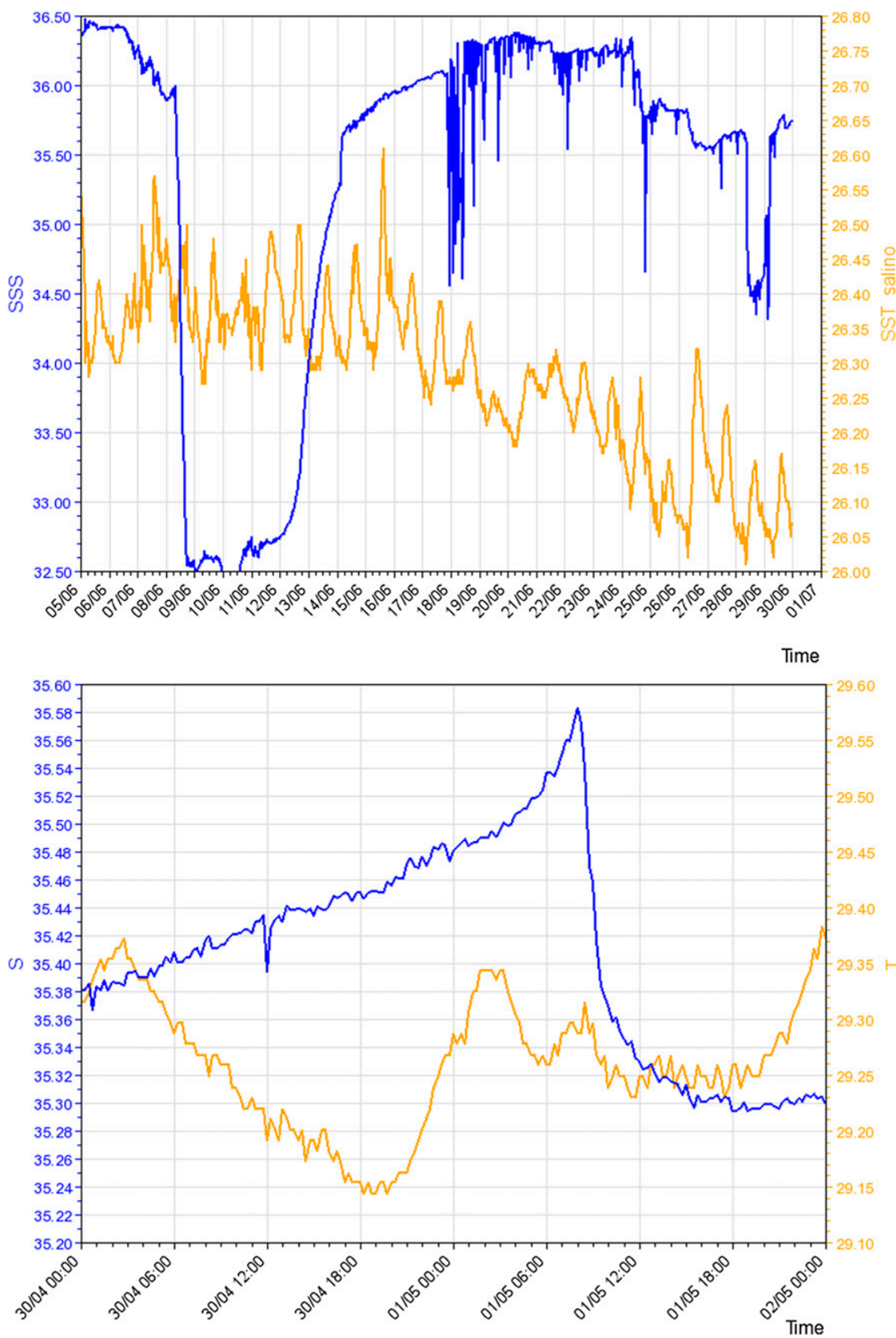

FIG. 2. Example of $S$ records ( $S$, blue; $T$, yellow). (top) A suspicious record for SVP-BS drifter PG109460 in June 2012 south of the equator in the tropical Atlantic. The very low values on 9-13 Jun are very unlikely and then there are noisy values at least for 18-25 Jun and possibly until July 2012, which cast strong doubts on this portion of the record. (bottom) Example of positive deviation in $S$ (Surplas drifter 29841) from 30 Apr to 2 May 2011 near $180^{\circ} \mathrm{W}$. This is also seen (but at a lesser resolution) on an attached PG SVP-BS drifter. The positive $S$ (and density) spike happens in the late (local) evening (0800 UTC 1 May).

isolated negative deviations. However, on drifter salinity data, we found that most rainfall-caused salinity drops at $50 \mathrm{~cm}$ larger than 0.1 psu last for at least an hour (Reverdin et al. 2012). Thus, these data would not be identified as erroneous by the test, in particular for PG data reported every $30 \mathrm{~min}$. More surprisingly, there are also cases of positive salinity spikes that are real, as can be verified from the data of independent attached floats (bottom panel of Fig. 2 presents such an example). Usually, there is a correlation between $T$ and $S$ variations 

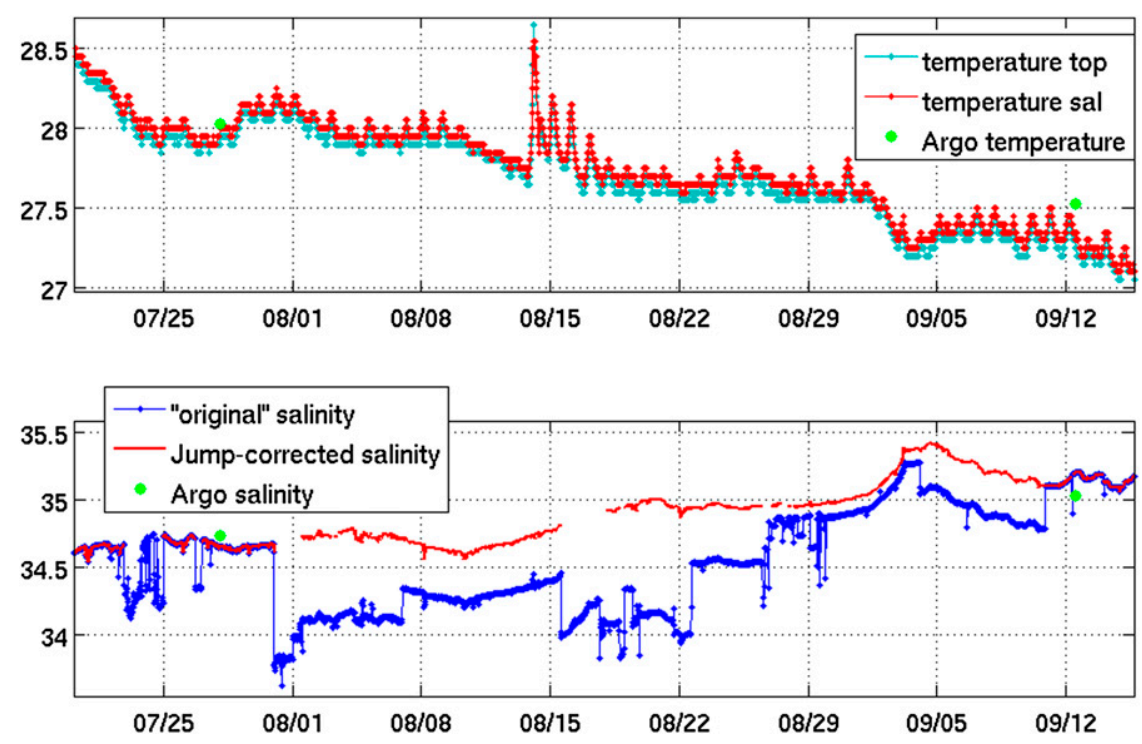

FIG. 3. Data from SVP-BS drifter PG92546 between 22 Jul and 22 Aug 2010: (top) temperature (sal refers to the Sea-Bird sensor, whereas top refers to a hull thermistor) and (bottom) salinity (blue, original; red, corrected for jumps; green dots, nearby Argo data).

for such events, although this is not so obvious in Fig. 2, bottom. Notice that in this case the data were correctly not detected as erroneous. Values that fail the "spike" test are removed, which, for example, results in the removal of $0.4 \%$ of the data for long-lived PG92546. This test is not carried out systematically for ICM/CSIC drifters, as their data are usually noisier and for some of these drifters are only transmitted $6 \mathrm{~h}$ each day. For these data, we also apply a subjective elimination of outliers. The test was also not applied on 15 SVP-S drifters (10 in the South Pacific and 5 in the Nordic seas) for which there were considerable gaps in the data records due to transmission errors (checksum test).

We then remove $S$ values during midday warming periods on SVP-BS drifter data, as we had shown [for the Campaign for Validating the Operation of the Soil Moisture and Ocean Salinity Mission (COSMOS) 2005 experiment drifters] that the depth mismatch between $\mathrm{C}$ and $\mathrm{T}$ sensors can be the origin of large midday errors (Reverdin et al. 2007). Thus, when the maximum temperature exceeds by more than $0.8^{\circ} \mathrm{C}$ the lowest morning temperature, midday [1100-1500 local time (LT)] $S$ data are checked and removed, if they present a variability larger than $0.01 \mathrm{psu}$ during this period of the day. This removed 3\% of the data for PG92546 in the western equatorial Pacific. However, this test cannot be applied for the subset of ICM/CSIC drifters that transmitted data only between 0000 and 0600 UTC each day. It has also not yet been applied to SVP-S drifter data.

The next step is to identify periods (6 $\mathrm{h}$ to a month) with objects present in the cell that would have passed the first visual test and that are not associated with anomalously increased noise levels or isolated spikes. We expect that such episodes would usually be associated with sudden changes in $S$ but no change in $T$, contrary to the crossing of fronts, where both $T$ and $S$ changes are identified, or rainfall events, which can induce drops both in $S$ and (to a lesser extent) $T$ (Reverdin et al. 2012). We thus have checked all the jumps in $S$ of 0.1 psu or more and investigated whether they are associated with temperature changes. If this is the case, then we usually chose to adjust the later salinity data in order to compensate for the jump, but also to verify consistency with later comparisons to other in situ data.

We will discuss issues in applying this method. One difficulty is that the associated variations in $T$ that could be related to a front are not always large enough to be detected in the presence of a daily temperature cycle or when the resolution of the temperature data is equal or lower than $0.05^{\circ} \mathrm{C}$, as was the case in early drifter models (Metocean models with Argos transmission and the PG models before 2011). Examples are presented in appendix A, which illustrate that the correction method can result in the correction of real salinity jumps, although in many other cases it results in correcting false jumps.

In some records, many jumps are identified as artificial (no associated temperature jumps) with resulting data adjustment. This situation is encountered on large portions of the drifter PG92546 record in Fig. 3. This drifter was in a region of very large surface freshening due to rainfall (Reverdin et al. 2012), and thus one expects that there can also be frequent crossing of surface fronts. The 

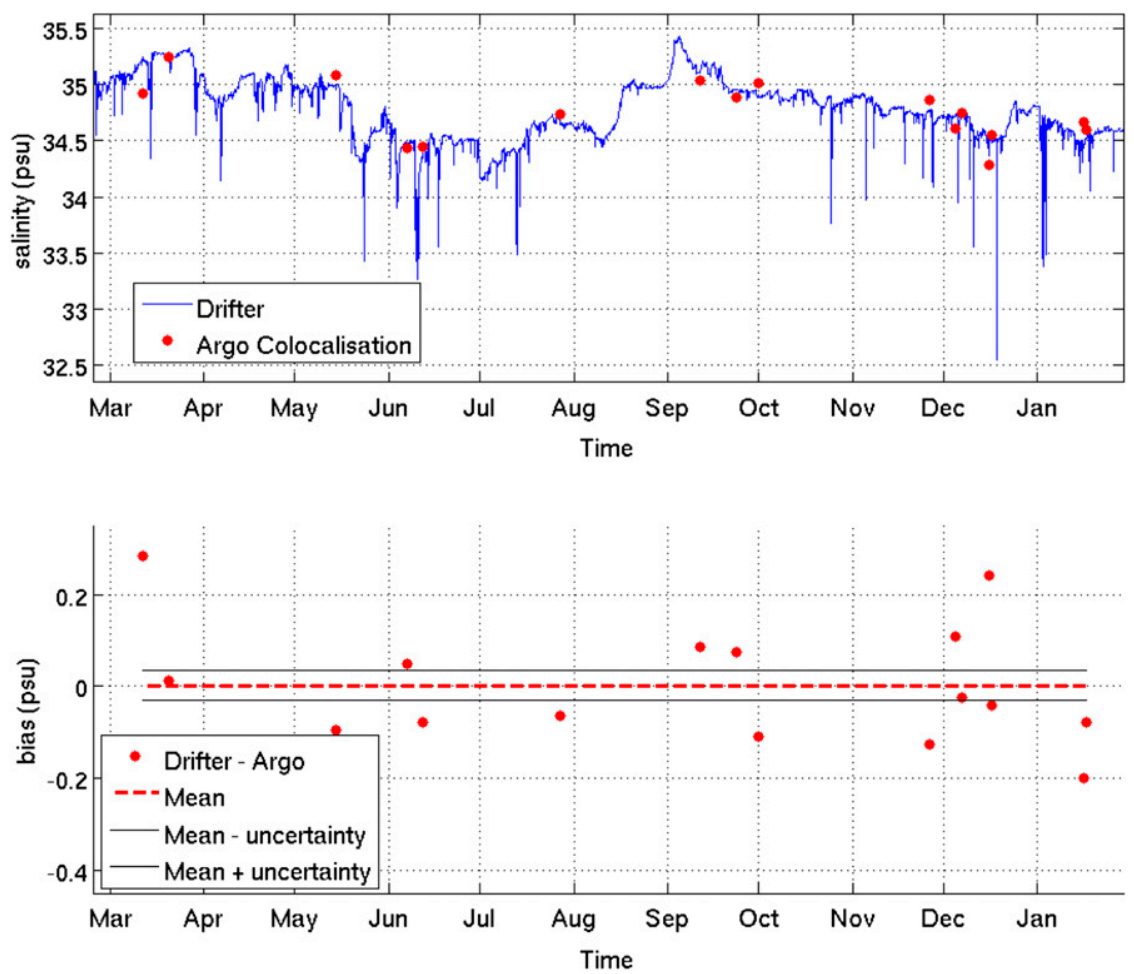

FIG. 4. (top) Jump-corrected $S$ records of PG92546 drifter with the collocated Argo profiles values (red) from February 2010 to January 2011. (bottom) Differences in $S$ between drifter and Argo (red dots) with the suggested bias based on the median difference (dashed line with the $1 \sigma$ uncertainty range).

corrections will lead to larger errors, as it is not guaranteed that all the corrected jumps were erroneous, even though in this particular record there is a tendency for negative jumps to be corrected by later positive jumps. The portion of the record corrected in this way for this long-lived drifter is large (25\% of this 16 -month record). The resulting jump-adjusted record in August 2010 is certainly suspiciously smooth. We thus expect that the jump-corrected parts of the records have larger errors than other portions of the record. Therefore, they are considered class B data. The class A category for this drifter also includes later data, but for which collocated in situ data suggest that drifter $\mathrm{S}$ does not present a large bias. Adjusting the salinity records to remove completely the jumps also adds an uncertainty of twice the "noise" (rapid variability before and after the jump). This is very often at least $0.05 \mathrm{psu}$.

In the western tropical Atlantic off northeastern South America, many drifters present very large salinity variability near the shelf break and in regions where we expect seasonal freshwater associated with the plumes of the Amazon and Orinoco Rivers. Many sudden salinity changes are seen in the drifter data in this region in June through October that do not appear closely related to temperature changes, and reported salinity can be as low as 28 psu. We thus checked whether the low salinities and large variability in the drifter records are compatible with the SMOS data that are available since 2010. The comparisons usually suggest that a large part of these sudden changes in $S$ and very low drifter salinities might be real features (see examples in appendix B). Thus, the jump correction algorithm is not applied in this region.

\section{Validation with in situ data}

\section{a. Argo data}

To check the final processed and jump-corrected records and to identify possible salinity biases, we compare them with salinity (between 5- and 10-m depths) of nearby Argo floats. We retain data extracted from the Coriolis database that have either been corrected in remote mode or have a valid real-time flag. We first extract Argo data within 2 days and $100 \mathrm{~km}$ of the drifter, then selecting in the drifter records the data at the time for which the drifter is closest in space (Fig. 4). We then require that the Argo temperature is within 
$0.3^{\circ} \mathrm{C}$ of the temperature measured by the drifter in the closest night and that there is no evidence for simultaneous rainfall events or front crossing on the drifter data ( $\mathrm{rms}$ less than $0.025 \mathrm{psu}$ in one day). Data on shelves (ocean depth less than $200 \mathrm{~m}$ ) or within $400 \mathrm{~km}$ of the Amazon estuary and $150 \mathrm{~km}$ of the Garone estuary are also ignored; these criteria together eliminate two-thirds of the collocalizations. Nonetheless, these criteria leave a contribution of mesoscale variability in the differences induced by the separation (in the South Pacific subtropical gyre near $20^{\circ} \mathrm{S}$, an analysis of variability along 23 ship-of-opportunity thermosalinograph sections in 2010-11 indicates a correlation length of $95 \mathrm{~km}$; in the central subtropical North Atlantic in August-September 2012, we investigated surface structures of width on the order of $10 \mathrm{~km}$ with cross-gradient variations of $0.2 \mathrm{psu}$, and a spatial rms variability on the order of $0.07 \mathrm{psu}$ over a $100 \mathrm{~km} \times 100 \mathrm{~km}$ box).

In this instance of long-lived drifter PG92546, the median of the comparisons is not distinguishable from 0 with an uncertainty of $0.025 \mathrm{psu}$ (based on the scatter in the individual comparisons) for the first year of the record (Fig. 4). The spread of the points (0.11 psu rms), however, is too large to identify portions of the record with errors less than $0.1 \mathrm{psu}$, which would result from the adjustment method for the jumps (there are three collocated Argo float data for the adjusted portions in late November 2010 and in January 2011 with scatter comparable to other periods).

However, when considering all the SVP-BS records, the drifter data uncorrected from biases are usually coherent with collocated Argo data, with the peak in the histogram of the differences within \pm 0.01 psu (Fig. 5a). There is a tendency (near the origin) for a slight asymmetry with more cases of drifter salinity being lower than Argo salinity. Indeed, for the drifter record of Fig. 4, the median of the comparisons in late 2010/early 2011 suggests a weak and not significant negative bias of -0.04 psu that we later corrected, as fouling could have occurred in this warmer season. Thus, because of this large scatter in the comparisons to Argo data, we estimate the class A data accuracy of this drifter to be $0.05 \mathrm{psu}$, although parts of the record probably have a much better accuracy, in particular just after deployment. A more negative view would be that part of the differences in comparison to Argo data is due to errors in the record that change in time and were not corrected. This puts the maximum possible uncertainty to $0.11 \mathrm{psu}$ (the rms difference) for this record.

The comparison with Argo float data was also done for the set of uncorrected PG SVP-S drifters in the South Pacific subtropical gyre, a region with low productivity and thus an expected weak fouling. This is also a region
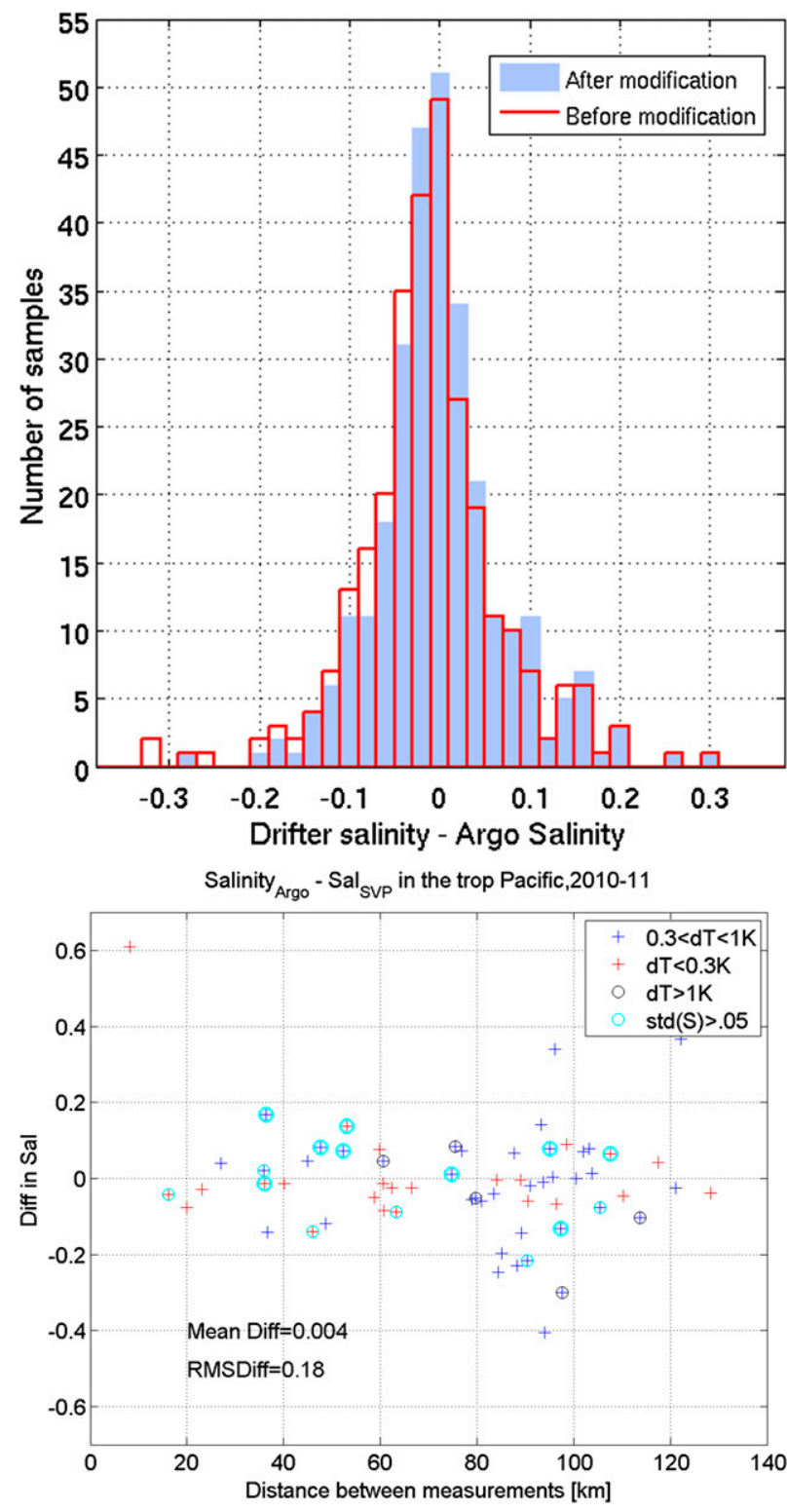

FIG. 5. Comparison of drifter S with upper-level (5-10 m) Argo float salinity. (top) Histogram of the differences (drifter S minus Argo S) for SVP-BS drifters (lines, before correction of biases; gray shading, after bias correction). (bottom) Individual differences for the set of SVP-S drifters in the South Pacific as a function of distance. Different criteria are used for selecting the points in the comparison (the red crosses fulfill all the criteria implemented for SVP-BS drifters, and the red crosses within a circle fulfill only the $T$ difference criteria). The point with a very large difference for a distance of $8 \mathrm{~km}$ was later identified as being from a suspicious record with jumps. Otherwise, no difference larger than $0.10 \mathrm{psu}$ is found for the red crosses.

where evaporation dominates and precipitation is less common. The comparisons show a little less scatter (Fig. 5 , bottom) for separations less than $50 \mathrm{~km}$ than for larger separations. There is also less scatter when the criteria 

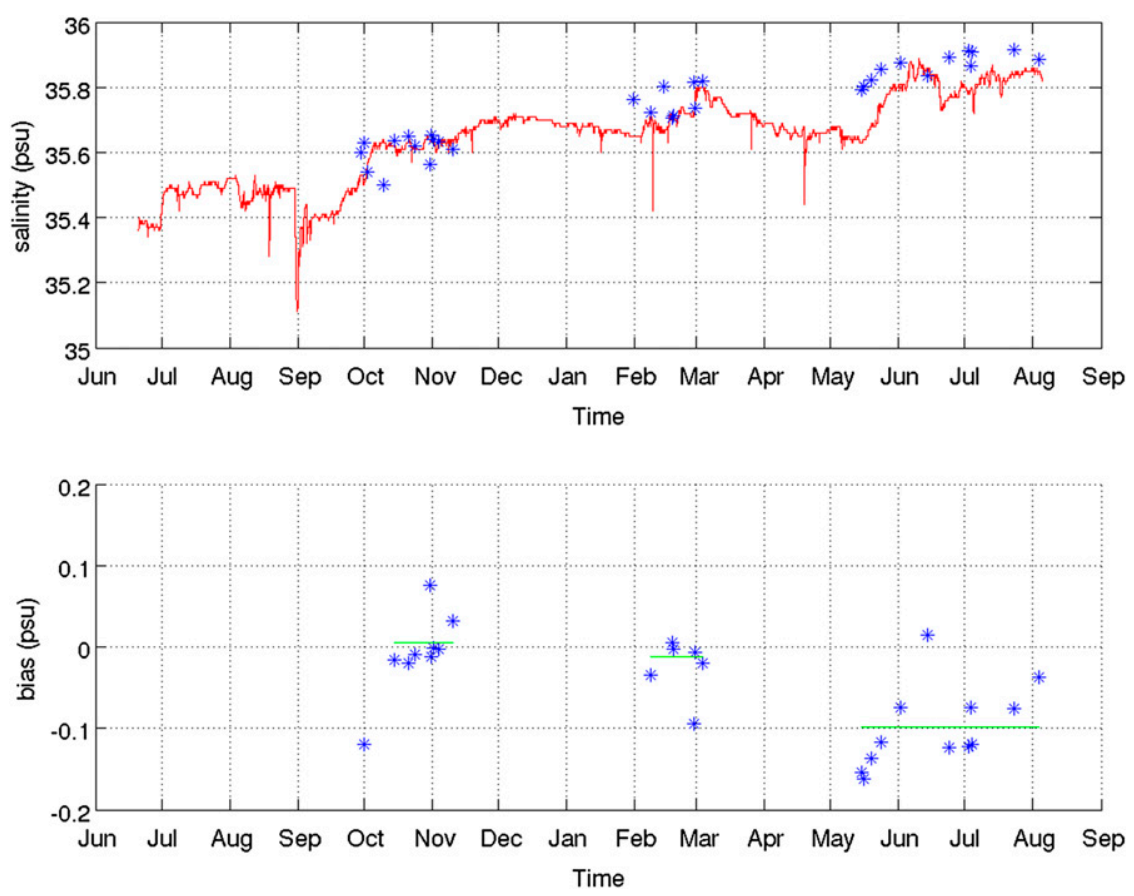

FIG. 6. Comparison of $S$ record for Metocean 3000340133307380 in the North Atlantic (201011) with Argo float upper-level $S$ (blue stars). (top) Time series. (bottom) Difference between drifter S and Argo S. As it is not clear when the drift developed, the part of the record after March $2011\left(46^{\circ}-47^{\circ} \mathrm{N}, 8^{\circ}-14^{\circ} \mathrm{W}\right)$ is placed in class $\mathrm{B}$, with a possible uncertainty of $0.1 \mathrm{psu}$ after bias correction.

presented above are used than when all collocated data are included. There is an average difference, with drifter salinity higher than Argo float salinity. This could result from vertical haline stratification with higher salinity at the surface than deeper at the Argo float level in this evaporation-dominated region. Thus, we do not find for the early portion of these SVP-S drifter data in the South Pacific the negative bias that was portrayed in the comparisons for SVP-BS drifters. The SVP-S salinity records as well as the ICM/CSIC records are also a bit noisier than the ones from the SVP-BS data and random errors might be larger.

The comparison with Argo float data has been done for all long-lived drifters and is a key source of information on drifter biases/errors. In addition to confirming the correction of possible large jumps/errors, the comparisons can sometimes identify (by grouping the comparisons over a long-enough period) a drift due to fouling of the conductivity cell. This was done, for example, for the 2005 drifter data in the Bay of Biscay (Reverdin et al. 2007). These comparisons usually indicate that the resulting bias is small in the first 6 months of the drifter life (except for some ICM/CSIC drifters). The comparisons have also been successful in estimating biases away from the equatorial and wet tropics. When there are enough validation data, the drift is estimated as a linear fit in time. In one instance of a long-lived drifter in the North Atlantic subpolar gyre and Nordic seas (PG84006) over close to $2 \frac{1}{2}$ years, the comparisons suggest that the bias presented a seasonal cycle and was smaller in wintertime, when fouling should be very small due to strong light limitation and frequent windy weather. In this case, we imposed an average shape of a seasonal cycle, but with corrected biases always smaller than 0.05 psu and an uncertainty in the corrections better than 0.02 psu. We have not been able to identify a similar seasonal dependency of the bias for other drifters.

Figure 6 illustrates an instance when a bias of $0.1 \mathrm{psu}$ was present in spring 2011, without having indications on when this developed. The later part of the biascorrected record since March 2011 is thus considered class B with a maximum uncertainty of $0.1 \mathrm{psu}$. This is at the high end of the bias correction that we applied on PG or Metocean drifters away from the equatorial region, and the uncertainties for those drifters are usually closer to the 0.02 psu level (class A). Biases are often larger on ICM/CSIC drifters. Figure 7 provides a typical comparison for an ICM/CSIC drifter for which there are clearly not enough points of comparison to reliably correct the whole record at the required $0.1 \mathrm{psu}$ uncertainty of class B data. 


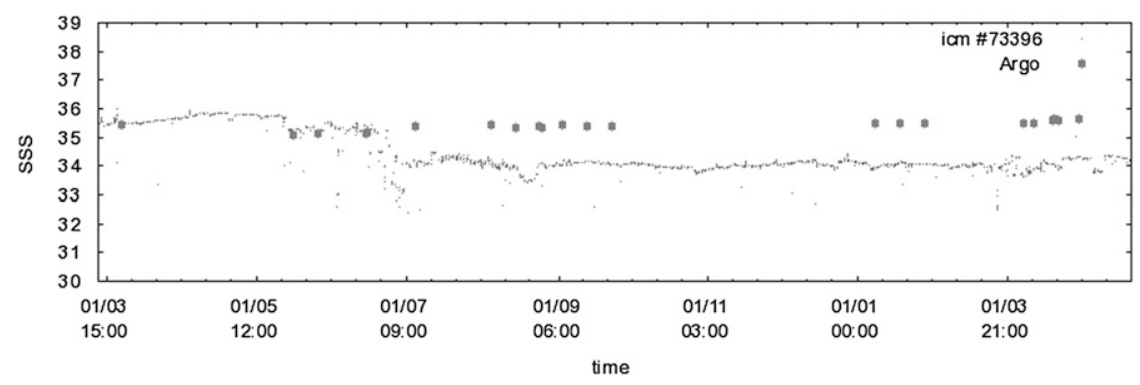

FIG. 7. Comparison of SVP drifter ICM73396 with Argo S (dots). Large data noise at the end of June 2011 , followed by large negative biases $\left(24^{\circ}-30^{\circ} \mathrm{S}, 54^{\circ}-70^{\circ} \mathrm{E}\right)$.

After correction of identified biases, we checked again the distribution of the differences with Argo data (Fig. 5, top). Not surprisingly, we have mostly removed the negative (drifter S less than Argo) tail of the distribution, and the distribution close to the origin is more symmetrical, although it remains slightly shifted toward smaller drifter salinities. The corrections reduce the overall standard deviation in the differences (from 0.081 to $0.073 \mathrm{psu}$ ), a reduction that does not originate from much changes in the outliers, but from a narrower distribution near the origin. The median is slightly changed by the corrections and becomes indistinguishable from 0 (before correction it was $-0.006 \mathrm{psu}$, a small but significant value). Similar changes are found for ICM/CSIC drifters, but with the caveat that the time series we retain are rather short and the statistics are not as good. There is also a much larger scatter in the comparisons due to the significant proportion of class B data (and also that we cannot in the same way select data away from fronts, as many ICM/CSIC drifters were only transmitting data from 0000 to 0600 UTC).

\section{b. Ship thermosalinograph data}

There are not many independent in situ data to check the corrections applied to the drifter data. However, drifter PG92546 was in a region crossed by four ships of opportunity of the Observatoire de Recherche en Environnement (ORE) SSS merchant ship observatory (Delcroix et al. 2007; Cravatte et al. 2009; Singh and Delcroix 2011) (www.legos.obs-mip.fr/observations/sss) for which validated and corrected thermosalinograph data are available in 2010. These ship data originate from water circuits pumping the water close to a depth of $5 \mathrm{~m}$. The thermosalinograph temperature is found on average $0.4^{\circ} \mathrm{C}$ larger compared to outside nighttime surface water temperature, but this might vary in time depending on the flow rate or temperature of the engine room. On the other hand, salinity is corrected based on daily water samples, and an estimated uncertainty is provided with the ship data, which is often better than 0.02 psu.
There were two instances of very close comparisons between the ship data and PG92546 (less than 1 day and $10 \mathrm{~km}$ ): on 6 August 2010, this suggests a drifter value larger by $0.06 \mathrm{psu}$; and on 25 November 2010, a drifter value larger by $0.12 \mathrm{psu}$. Both are in parts of the record that had very large corrections. These comparisons could also present a large uncertainty due to the combination of spatial variability in the ship TSG records and temporal variability in the drifter records, which are both associated with at least a 0.05 psu rms variability. Another comparison farther away ( $26 \mathrm{~km}$ and 2 days) on December 2 would lead a drifter salinity too low by $0.11 \mathrm{psu}$ and one in a portion of the record not corrected on 10 April 2010 (but a large separation of $53 \mathrm{~km}$ ), a drifter salinity too high by 0.04 psu (after deployment on 20 February 2010, the drifter salinity is too low by $0.034 \mathrm{psu}$ ). These independent comparisons support the statement that the records should be correct to within $0.1 \mathrm{psu}$ most of the time (with an average difference smaller than 0.02 psu for this set of five comparisons, and whether the drifter data were class A or class B). As mentioned earlier, this does not exclude the possibility of incorrect jump compensations made in the class B data, thus higher errors for parts of the record. Notice also that there are no comparisons, either with Argo float data or with ships of opportunity, for FebruaryJune 2011 class A data. Although the values are in the expected range (based on large-scale analysis of Argo data), larger errors are possible on this portion of the class A record.

The comparison with the ship of opportunity data in 2010 was also carried for the set of 10 uncorrected SVP-S drifters in the South Pacific subtropical gyre (Fig. 8). This comparison suggests differences smaller than $0.1 \mathrm{psu}$ for seven out of eight instances with separations less than $50 \mathrm{~km}$ and one day. The median difference for those data is $-0.01 \mathrm{psu}$. Dispersion seems larger for larger separations, but altogether the bias seems small for this dataset in a region of rather large evaporation and usually weak precipitations. There are fewer comparisons in 2011, 


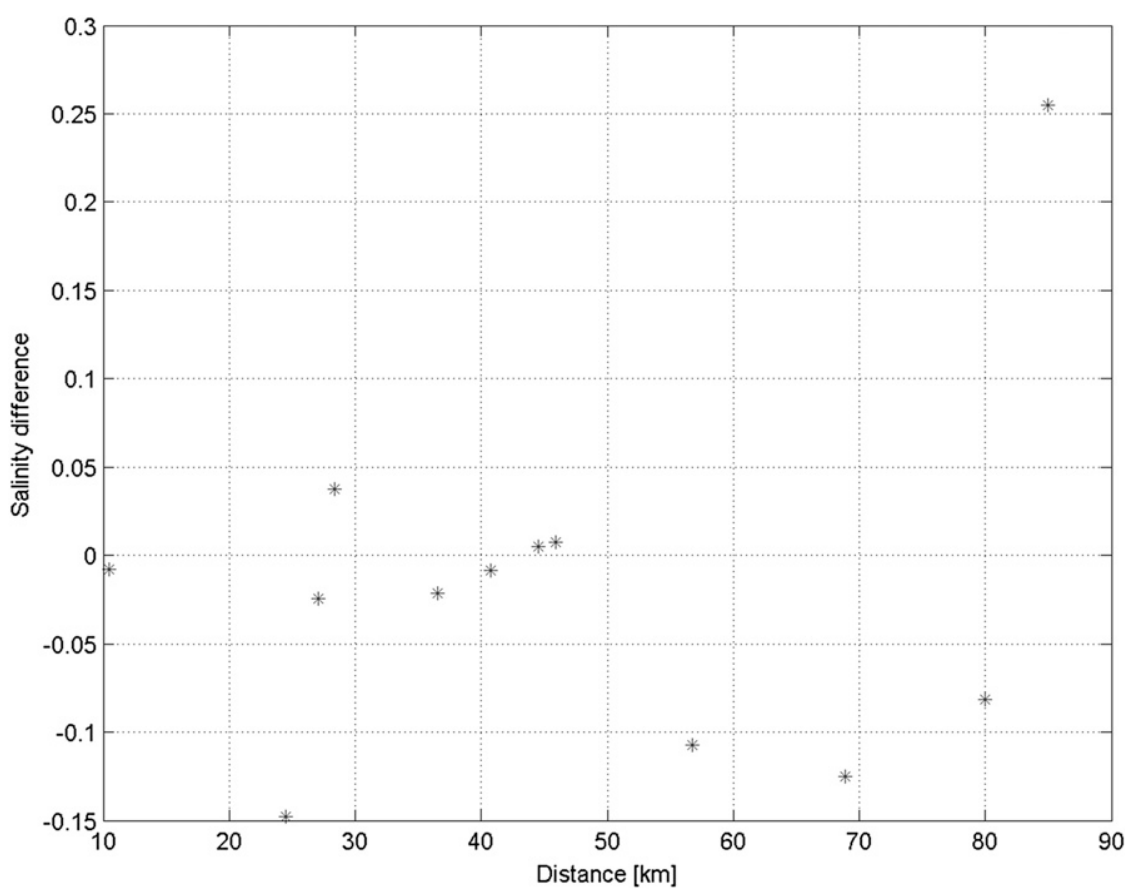

FIG. 8. Comparison of SVP-S S with ship TSG $S$ in the South Pacific in 2010. Differences (drifter minus ship $S$ ) presented as a function of distance.

but the available comparisons (not shown) suggest similar results to those in 2010, despite a longer time at sea.

\section{Discussion and summary}

Processed SMOS-derived weekly SSS seem to present errors of about $0.3 \mathrm{psu}$ in tropical regions, far from land and regions with high precipitation (Boutin et al. 2012a). Aquarius-derived weekly SSS probably have a comparable accuracy (Grodsky et al. 2014). The data used to validate these remotely derived surface salinity are mostly from Argo floats with uppermost measurements often near $6-7 \mathrm{~m}$, surface mooring measurements (at best near 1-2 m), and ship-mounted thermosalinographs (TSGs; pumping water usually between 4 and $10 \mathrm{~m}$ ). Mooring and ship-mounted TSGs suffer from platform effect (mixing induced by the structure) and fouling. Furthermore, there is the uncertainty in the comparisons resulting from the unmeasured stratification between instrument depth and the sea surface. This is particularly the case in tropical areas where intense rainfall contributes to surface freshwater lenses and haline stratification (Henocq et al. 2010).

We explored here whether surface drifters measuring salinity near $50 \mathrm{~cm}$ of the sea surface can provide additional data for SSS studies or for the validation of SSS derived from L-band radiometry on board satellites. We will put aside the issue that the drifters do not measure
SSS but salinity near $50-\mathrm{cm}$ depth, and that we might still have a noticeable haline stratification between the surface and $50 \mathrm{~cm}$ that has to be taken into account (Reverdin et al. 2012). The main issue is whether the drifter S accuracy is sufficient and better than the uncertainty resulting from salinity stratification above the measurements of other datasets (Argo, moorings, ship TSGs). For other applications, it is the additional spatial coverage that might be interesting in the drifter data, and for that the drifter data accuracy should be better than the unresolved horizontal variability.

We have examined with simple methods what could be the biases in the salinity measured by drifters and how they could be corrected. In addition to data during large daily SST cycles for some drifters (SVP-BS and SVP-S models) that are known to be biased and were removed, we have identified three kinds of bias behavior, described below.

1) Large drifts/biases due to fouling or accumulation of objects that persist for months or for the whole life of the drifter. Large fouling happened for most ICM/CSIC drifters, but it sometimes happened on Metocean and PG SVP-BS drifters, often after a year in the water. We also suspect that this might have happened for a few drifters in the tropical Atlantic Ocean. For a few ICM/CSIC drifters, salinity data 
presenting a large negative bias nonetheless featured the expected contrasts in $T$ and $S$ across fronts, and the bias estimated from the comparison with Argo data appeared stable enough in time. For those, we estimate that the comparisons with Argo data can be used to correct the data. It is however not reasonable to expect accuracy of the corrected data to be better than $0.1 \mathrm{psu}$, as the average correction is large, often larger than 0.5 psu.

2) Temporary biases that are probably due to objects stuck in the conductivity cell, that later on get expelled. The transition is through jumps in $S$ (but not in $T$ ). Sometimes, this is also associated with large noise in the salinity records, and these portions of the records are eliminated after an initial visual check. This seems to be an occasional occurrence in the wet tropics, but it also happened for short periods on a number of drifters in other regions. In other cases, there is no increase in noise, and we attempt to suppress the salinity jumps by shifting later parts of the record. There is evidence that this happens, based on simultaneous records by Surplas floats. Later collocated Argo floats suggest that the jump corrections do not degrade the record and that resulting errors on the corrected portions are at most on the order of $0.1 \mathrm{psu}$. However, we might have overidentified some jumps as being artificial on PG92546, because the resolution of $\mathrm{T}$ for this drifter was too low $\left(0.05^{\circ} \mathrm{C}\right)$, whereas for drifters in which resolution is $0.01^{\circ} \mathrm{C}$, the identification of these events is much less ambiguous, at least when the temperature daily cycles are not too large.

For some drifters within the Orinoco-Amazon plume region, we found identifying the jumps challenging as well as what should be considered a "noisy" record and what is a "correct" record. This is a region with very few Argo floats to validate the records and huge spatial gradients as illustrated by SMOS maps (cf. appendix B). In this region, vertical haline stratification can also be very large in the top $10 \mathrm{~m}$ (as an extreme case, a $2007 \mathrm{CTD} /$ drifter station near $5^{\circ} \mathrm{N}$ just off the shelf break indicated salinity gradients on the order of $1 \mathrm{psum}^{-1}$ between the surface and $6 \mathrm{~m}$ ). The comparisons with SMOS data suggest that a large part of the sudden changes in $S$ (but not in $T$ ) from the drifters in this region might be real features. However, there is also the possibility at times that artificial jumps or marginally noisy data due to the presence of objects stuck in the conductivity cell were not eliminated, and thus the uncertainty in the data can be as large as $0.5 \mathrm{psu}$, such that these drifter data should be considered class B data.
3) Slow drifts of the salinity. We were only able to identify them unambiguously for midlatitude drifters, based on the comparison with Argo floats. This seems to be happening at a varying degree to most drifters in the North Atlantic, possibly more in spring and summer [as was already discussed in Reverdin et al. (2007)]. However, there is no systematic ad hoc correction that we can propose that would work for all those drifters. When the proposed bias is less than the uncertainty due to the scatter in the individual bias estimates, we chose not to correct the salinity records. Thus, we never applied corrections for the initial portions of the records. Usually, the accuracy of the corrected salinity records will be better than $0.02 \mathrm{psu}$, but there are instances near the end of the drifter's life or when the drift accelerates and for which we will end up with higher errors after correction. We retain the corrected data within the category A when the uncertainty of the corrections is known to better than 0.1 psu. Obviously, these corrections may mask small but real vertical gradients.

Estimating the final accuracy of the data is clearly limited by the density of available useful collocalized data. Currently the most useful dataset for corrections is from the Argo float database. This has different implications: first, not all of the Argo data that we used have been validated (for 2010, roughly 50\% were not yet validated), and biases in the data retained could still be on the order of 0.01 psu in $5 \%-10 \%$ of the floats (Riser et al. 2008). Second, because of the Argo data density, comparisons are meaningful only when there are at least 6 months of drifter data, and the individual comparisons still present a large standard deviation of at least $0.05 \mathrm{psu}$ at midlatitude and closer to 0.1 psu in the tropics. Hence, many collocalizations are necessary to reduce the uncertainty in the bias estimate. Third, the Argo data are deeper than where the drifters measure salinity, and there can be haline stratification. However, the Argo data are used in the comparisons only when the drifter salinity presents little time variability (over $24 \mathrm{~h}$ ), and the temperatures of the drifter and the Argo float are close in order to minimize the occurrence of situations with haline stratification.

We should also comment as a caveat that we derived the accuracy of the drifter records from the averaged difference to Argo salinity, and that we attribute the rms difference to the spatiotemporal variability between the two measurements. A more pessimistic approach would be that the errors in the records are more random, and thus that the rms difference between Argo and the drifter record originates from a drifter error combined with spatiotemporal variability. With the estimate of 
spatiotemporal variability just commented (on the order of $0.05-0.1$ psu from midlatitudes to tropical areas and away from western boundary currents or the wet tropics), the comparisons presented could imply larger random errors than the accuracy estimated from the error on an average bias.

Altogether, out of 14500 SVP-BS drifter days, we retain 12100 days with salinity data in categories A or B, out of which 1830 days (16\%) were corrected for a bias. There are still numerous cases of long-lived drifters when the records only corrected for instance 2, seem consistent with Argo floats for periods of a year or more, without any bias correction. This was also the case for most SVP-S drifters deployed in the southwest Pacific in 2010. Even for PG92546 in the southwest tropical Pacific, away from $25 \%$ of the record that was jump corrected, a small correction based on the comparisons with Argo floats was only applied for the second year (this correction is debatable, as the applied negative bias was not statistically significant at the $90 \%$ confidence level). Altogether, in the data retained, two categories of data are considered. The most accurate one (class A) includes the data with no large jumps to be corrected and no large fouling. For them, the accuracy could be at times as good as $0.01 \mathrm{psu}$, but in most cases, collocalization with the Argo data cannot prove the accuracy to be better than 0.02 psu at midlatitudes and 0.05 psu in the tropics (assuming that the only error is in the average bias). Independent validation with ship TSGs suggests that these uncertainty estimates are reasonable. These errors are clearly within the spatial mesoscale salinity variability signals in these regions. They are also sufficient to investigate near-surface stratification in the presence of rainfall. The less accurate data are in class B, for which jump adjustments or large bias corrections had to be applied, and for which an overall accuracy of $0.1 \mathrm{psu}$ is attributed, but that cannot be guaranteed. This should be sufficient in regions of large spatial variance, either in the wet tropics or near ocean fronts. Drifters in the northwestern tropical Atlantic Ocean presenting a large variability are also lumped into this category. The variability is coherent with what is expected from SMOS maps. However, these drifter data cannot be verified by other in situ observations, and it is possible that records include anomalously low or noisy values due to objects stuck in the cell, which occasionally could result in biases on the order of -0.5 psu. Even those errors would be less than the large spatial variability and also less than the differences with other (deeper) observations due to large regional vertical stratification.

Further progress on the data validation of drifter data will be accomplished during dedicated experiments with a higher density of observations, in particular for the
Salinity Processes in the Upper Ocean Regional Study (SPURS) experiment in 2012-13 in the North Atlantic subtropical gyre. Instrumented drifters will also continue to be deployed for SMOS and Aquarius calibration and validation in the "wet" tropics. In these regions, it will be very interesting to have simultaneous measurements of winds/waves and rainfall in order to better diagnose the changes in surface salinity and near-surface stratification. This should complement data obtained from Argo floats implemented with sensors for near-surface measurements at high vertical resolution (S. Riser 2013, personal communication).

Acknowledgments. This effort is part of ESA SMOS calibration and validation projects, and is supported nationally in France by CNES/TOSCA with the GLOSCAL project; in Spain, at ICM/CSIC by the Spanish national $\mathrm{R}+\mathrm{D}$ plan (Projects AYA2010-22062-C05 and CSD200800077). In Germany funding was provided by BMBF to CEN under Contracts 50EE0934 and 50EE1245, as well as by the DFG in the frame of SFB512. The deployments and recoveries of drifters were done from a large array of national research vessels and opportunity merchant or sailing vessels to whom we are highly indebted. The validated SVP-BS and ICM/CSIC drifter data can be retrieved under "regions" (http://www.locean-ipsl.upmc. $\mathrm{fr} / \mathrm{smos}$ /drifters). Thermosalinograph data were provided in the western tropical Pacific Ocean by the ORE SSS (www.legos.obs-mip.fr/observations/sss).

\section{APPENDIX A}

\section{Salinity Jumps}

Examples of variability when a Surplas float was attached to the drifter illustrate the issue on how to detect erroneous salinity jumps. In Fig. A1, there is a sudden jump in $S$ on 23 June that is associated with a small change in $T$ (on the order of $0.05^{\circ} \mathrm{C}$ ). There is a second jump in $S$ on 24 June associated with a slightly larger change in $T$, and a third one on 26 June with no clear change in $T$. We did not correct it, on the basis of later comparisons to Argo data. This jump is also found in the Surplas data (not shown, as they start to present large fouling) and thus is real. However, it would have been mistakenly identified as erroneous without these data or the later comparison to later collocated Argo floats. Furthermore, if the temperature records had only a resolution of $0.05^{\circ} \mathrm{C}$ or less as on early drifters, the 24 June jump could also have been mistakenly identified as artificial.

Figure A2 shows other examples of salinity variability. It presents two low salinity events associated with rainfall 

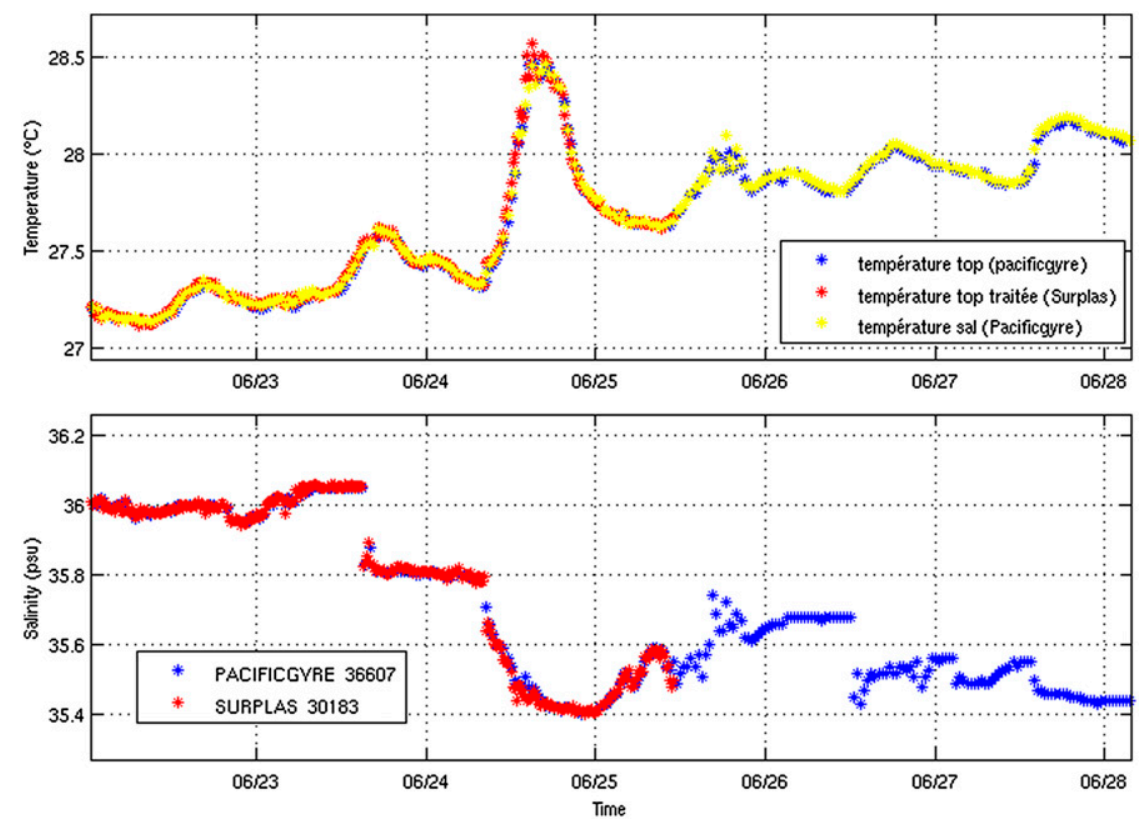

FIG. A1. Zoom in the time series from PG36607 and Surplas 30183 in June 2011, near $2^{\circ} \mathrm{N}, 32^{\circ} \mathrm{W}$ (UTC time). (top) $T$; (bottom) $S$ (red, for Surplas, and blue for PG data).

on 25 and 29 July 2011. These are associated with $T$ changes and would have been identified as real. Then, there is a negative jump in $S$ on 28 July, a period of noisy data on $30 \mathrm{July}$, and a positive jump on 31 July. As there was no temperature change associated with the decrease of $S$ on 28 July or the increase on 31 July, the hypothesis would have been (correctly) that the drop was accidental (object stuck in the cell) and the following record would have been shifted upward until 31 July (with the noisy data on 30 July removed). In this particular case, later portions of the record present no bias compared to collocated Argo data, and thus without the Surplas record the corrections would still have been done correctly. However, there were other cases when positive

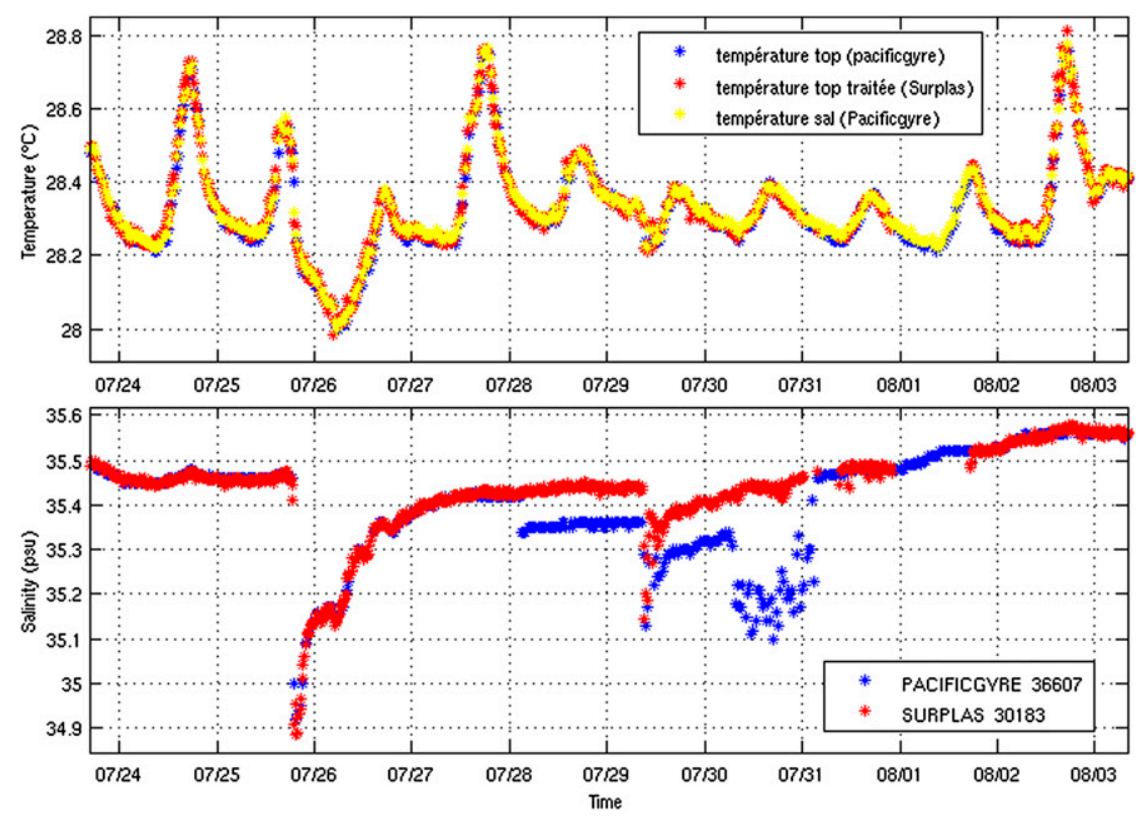

FIG. A2. Time series from drifter PG36607 and its attached Surplas 30183 deployed in 2011 in the equatorial Atlantic: (top) $T$ and (bottom) $S$ (red, for Surplas, and blue for PG data). 

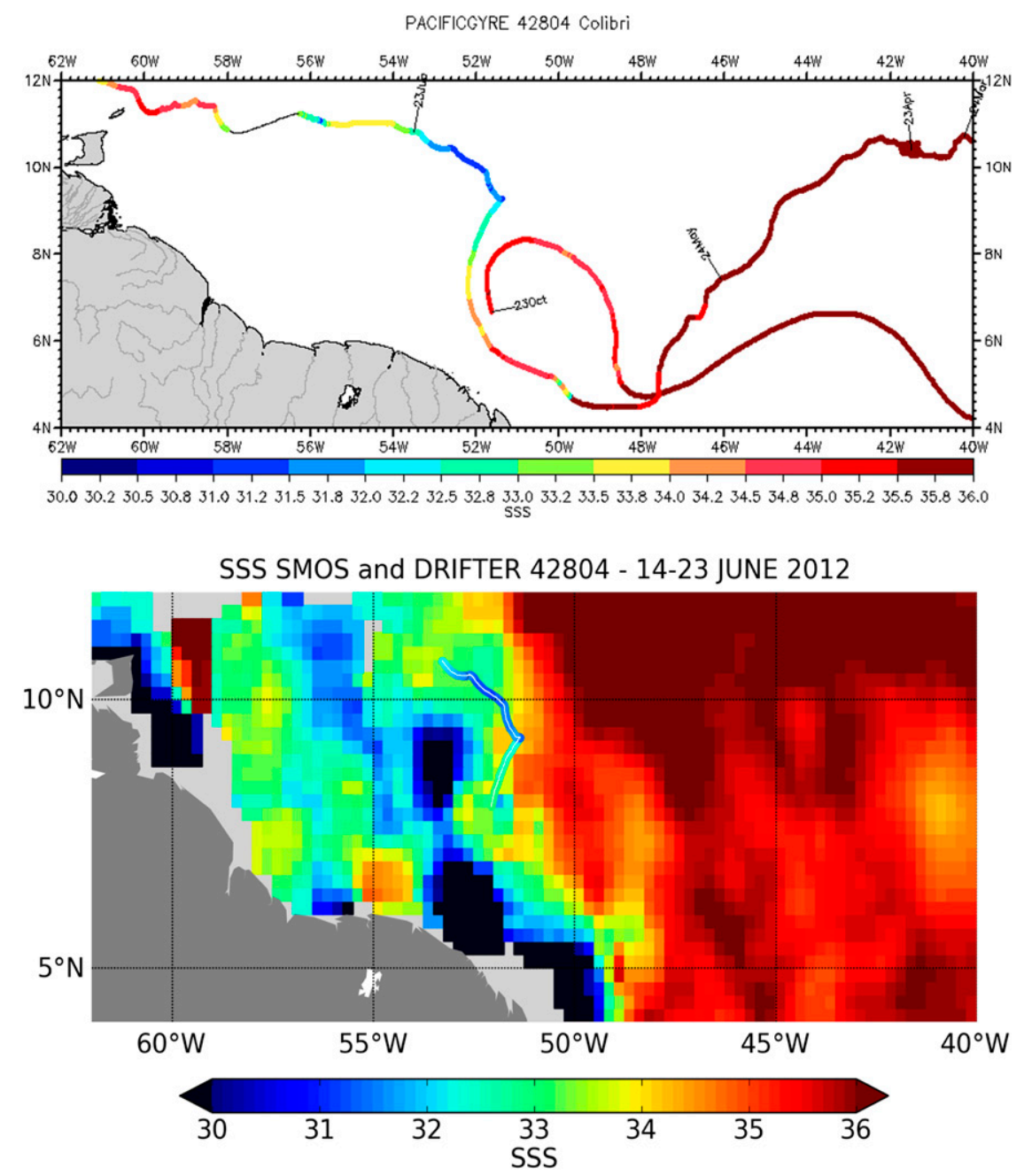

FIG. B1. Comparison of PG42804 SSS with collocated SMOS data in May and June 2012. (top) Trajectory color coded with $S$, whereas (bottom) a short period of the trajectory (14-23 Jun) (colored dots) overlaid with a composite map containing SMOS SSS averaged over the period and over $100 \mathrm{~km} \times 100 \mathrm{~km}$ (see Boutin et al. 2012a).

jumps do not have similar amplitudes to the earlier negative jump, and uncertainty in the data validation will be higher in those cases.

These two examples illustrate that adjusting the later salinity data by compensating the jumps, as we have done, is usually reasonable, but that it can also introduce significant errors in the data.

\section{APPENDIX B}

\section{Comparisons with SMOS Products off Northwest South America}

We considered nearby collocated SMOS data for drifters in this region. These SMOS data originate from
SMOS level 2, version 5 data of the European Space Agency (ESA) processing with the flag sorting described in Boutin et al. (2012a), except that the galactic noise flag was not tested (data affected by large galactic noise are nevertheless sorted out) and that land mask is only $40 \mathrm{~km}$. We also add a correction in the near-real-time product for 2012, adjusting the average SMOS value to climatology in the "OTT region" (southeast Pacific Ocean: $45^{\circ}-5^{\circ} \mathrm{S}, 140^{\circ}-95^{\circ} \mathrm{W}$ ). These data are fairly noisy, and their range of variations is usually consistent with the variability in the drifter data. To get a better sense on the spatial structures involved, we present maps averaged over roughly 10 days and $100 \mathrm{~km} \times 1000 \mathrm{~km}$ that are sampled on a $0.25^{\circ} \times 0.25^{\circ}$ grid. The maps are obtained using the weight averaging method described in Boutin et al. (2012b). We illustrate the comparisons with two 


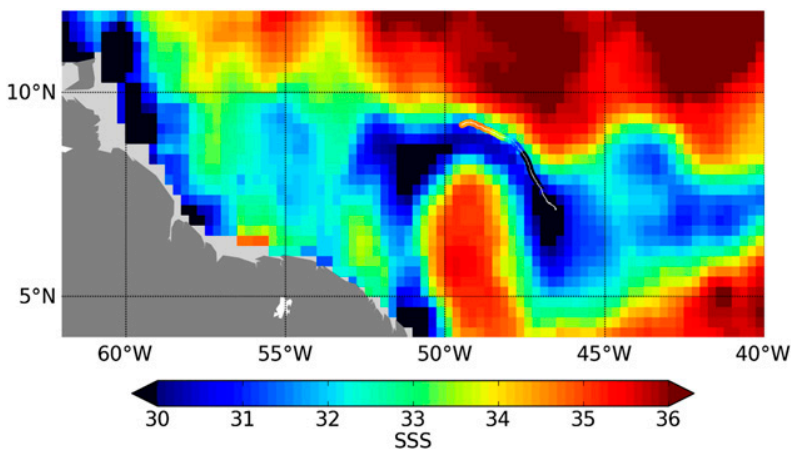

FIG. B2. As in (bottom) in Fig. B1 for a short period (11-20 Sep 2011) of the trajectory of drifter PG73226. Drifter is entrained in the retroflection of the North Brazil Current, probably on its outer rim

typical situations (Figs. B1, B2). PG42804 in June 2012 (Fig. B1) presents in particular a huge $S$ drop on 9 June (near $4.8^{\circ} \mathrm{N}, 50^{\circ} \mathrm{W}$ ) with no simultaneous $T$ change and later on drops down to 31.3 psu on 18-21 June farther north. Some of the largest changes in salinity correspond also to changes in the trajectory, in particular this later event, and thus we are suspicious that they correspond to the crossing of fronts. The SMOS maps suggest large time variability of the freshwater pattern in this region during June. The example presented for 14-23 June illustrates that the drifter had indeed been along the edge of the freshwater, which is inshore of its trajectory typical of the North Brazil Current separation, and that on 18 June it crosses a freshwater tongue in the SMOS maps. The observed SSS variability in drifter data seems thus coherent with the SMOS mapped situation, although the deviations with the mapped data can be locally on the order of 1 psu.

The other example shown for drifter PG73226 on 1020 September 2010 (Fig. B2) also presents a huge freshwater tongue, which in this case is clearly associated with the North Brazil Current retroflection. The SMOS map and the drifter find SSS values less than 30 psu in this tongue, although local deviations between the two datasets can reach 1 psu. These and other examples suggest that a large part of these sudden changes in $S$ (but not in $T$ ) from the drifters in this region might be real features.

\section{REFERENCES}

Banks, C. J., C. P. Gommenginger, M. A. Srokosz, and H. M. Snaith, 2012: Validating SMOS ocean surface salinity in the Atlantic with Argo and operational ocean model data. IEEE Trans. Geosci. Remote Sens., 50, 1688-1702, doi:10.1109/ tgrs.2011.2167340.
Boutin, J., and Coauthors, 2011: Sea surface salinity from SMOS satellite and in situ observations: Surface autonomous drifters in the tropical Atlantic Ocean. Extended Abstracts, First SMOS Science Workshop, Arles, France, ESA and CNES [Available online at http://earth.eo.esa.int/workshops/smos science_workshop/SESSION_3_OCEAN_SALINITY/J.Boutin_ SMOS_Satellite_Sea_Surface_Salinity_situ.pdf.]

_ , N. Martin, G. Reverdin, X. Xin, and F. Gaillard, 2012a: Sea surface freshening inferred from SMOS and Argo salinity: Impact of rain. Ocean Sci. Discuss., 9, 3331-3357, doi:10.5194/ osd-9-3331-2012.

,-- , Y. Xiaobin, J. Font, N. Reul, and P. Spurgeon, 2012b: First assessment of SMOS data over open ocean: Part II-Sea surface salinity. IEEE Trans. Geosci. Remote Sens., 50, 1662 1675, doi:10.1109/tgrs.2012.2184546.

Cravatte, S., T. Delcroix, D. Zhang, M. McPhaden, and J. LeLoup, 2009: Observed freshening and warming of the western Pacific warm pool. Climate Dyn., 33, 565-589, doi:10.1007/ s00382-009-0526-7.

Cronin, M. F., and M. J. McPhaden, 1999: Diurnal cycle of rainfall and surface salinity in the western Pacific warm pool. Geophys. Res. Lett., 26, 3465-3468.

Delcroix, T., S. Cravatte, and M. J. McPhaden, 2007: Decadal variations and trends in tropical Pacific sea surface salinity since 1970. J. Geophys. Res., 112, C03012, doi:10.1029/ 2006JC003801.

Durack, P. J., and S. E. Wijffels, 2010: Fifty-year trends in global ocean salinities and their relationship to broad-scale warming. J. Climate, 23, 4342-4362.

Font, J., and Coauthors, 2010: SMOS: The challenging sea surface salinity measurements from space. Proc. IEEE, 98, 649-665.

- and Coauthors, 2013: SMOS first data analysis for sea surface salinity determination. Int. J. Remote Sens., 34, 3654-3670, doi:10.1080/01431161.2012.716541.

Gordon, A. L., and C. F. Giulivi, 2008: Sea surface salinity trends over fifty years within the subtropical North Atlantic Oceanography, 21, 22-31.

Grodsky, S. A., R. Lumpkin, and J. A. Carton, 2011: Spurious trends in global surface drifter currents. Geophys. Res. Lett., 38, L10606, doi:10.1029/2011GL047393.

,,,--- and V. Coles, 2014: Year-to-year salinity changes in the Amazon plume: Contrasting 2011 and 2012 Aquarius/ SACD and SMOS satellite data. Remote Sens. Environ., 140, 14-22, doi:10.1016/j.rse.2013.08.033.

Henocq, C., J. Boutin, F. Petitcolin, G. Reverdin, S. Arnault, and P. Lattes, 2010: Vertical variability of near-surface salinity in the tropics: Consequences for L-band radiometer calibration and validation. J. Atmos. Oceanic Technol., 27, 192-209.

Johnson, G. C., and S. E. Wijffels, 2011: Ocean density change contributions to sea level rise. Oceanography, 24, 112-121.

Lagerloef, G., and Coauthors, 2010: Resolving the global surface salinity field and variations by blending satellite and in situ observations. Proceedings of OceanObs'09: Sustained Ocean Observations and Information for Society, Vol. 2, J. Hall, D. E. Harrison, and D. Stammer, Eds., ESA Publ. WPP-306, doi:10.5270/OceanObs09.cwp.51.

Reul, N., J. Tenerelli, J. Boutin, B. Chapron, F. Paul, E. Brion, F. Gaillard, and O. Archer, 2012: Overview of the first SMOS sea surface salinity products. Part I: Quality assessment for the second half of 2010. IEEE Trans. Geosci. Remote Sens., 50, 1636-1647, doi:10.1109/tgrs.2012.2188408.

Reverdin, G., 2010: North Atlantic subpolar gyre surface variability (1895-2009). J. Climate, 23, 4571-4584. 
- J. Boutin, A. Lourenco, P. Blouch, J. Rolland, P. P. Niiler, W. Schuba, and A. Rios, 2007: Surface salinity measurementsCOSMOS 2005 experiment in the Bay of Biscay. J. Atmos. Oceanic Technol., 24, 1643-1654.

— S. Morisset, J. Boutin, and N. Martin, 2012: Rain-induced variability of near sea-surface $\mathrm{T}$ and $\mathrm{S}$ from drifter data. J. Geophys. Res., 117, C02032, doi:10.1029/2011JC007549.

_ _ and Coauthors, 2013: Near-sea surface temperature stratification from SVP drifters. J. Atmos. Oceanic Technol., 30, 1867-1883.

Riser, S. C., L. Ren, and A. Wong, 2008: Salinity in Argo. Oceanography, 21, 56-67.

Roemmich, D., and Coauthors, 2009: Argo: The challenge of continuing 10 years of progress. Oceanography, 22, 46-55.

Schmitt, R. W., 2008: Salinity and the global water cycle. Oceanography, 21, 12-19.

Singh, A., and T. Delcroix, 2011: Estimating the effects of ENSO upon the observed freshening trends of the western tropical
Pacific Ocean. Geophys. Res. Lett., 38, L21607, doi:10.1029/ 2011 GL049636.

Terray, L., L. Corre, S. Cravatte, T. Delcroix, G. Reverdin, and A. Ribes, 2012: Near-surface salinity as nature's rain gauge to detect human influence on the tropical water cycle. J. Climate, 25, 958-977.

Ulaby, F. T., R. K. Moore, and A. K. Fung, 1986: From Theory to Applications. Vol. 3, Microwave Remote Sensing - Active and Passive, Artech House, 1120 pp.

Von Schuckmann, K., and P.-Y. Le Traon, 2011: How well can we derive global ocean indicators from Argo data. Ocean Sci., 7, 783-791, doi:10.5194/os-7-783-2011.

, F. Gaillard, and P.-Y. Le Traon, 2009: Global hydrographic variability patterns during 2003-2008. J. Geophys. Res., 114, C09007, doi:10.1029/2008JC005237.

Zhang, Y., and X. Zhang, 2012: Ocean haline skin layer and turbulent surface convections. J. Geophys. Res., 117, C04017, doi:10.1029/2011JC007464. 